\title{
POLÍTICAS PÚBLICAS DE EDUCAÇÃO AMBIENTAL DA SECRETARIA ESTADUAL DE EDUCAÇÃO DE SANTA CATARINA: UMA ANÁLISE CRÍTICA
}

\author{
Adriana Lima Moraes ${ }^{1}$; Carlos Frederico Bernardo Loureiro ${ }^{2}$
}

\begin{abstract}
RESUMO
O presente artigo analisa o processo de construção das políticas públicas de educação ambiental da Secretaria de Educação de Santa Catarina, tomando como ponto de partida o ano 1991, quando da elaboração de sua primeira proposta curricular. Para tanto, a pesquisa utilizou como procedimento metodológico a análise documental. $\mathrm{O}$ argumento orientador parte do entendimento das políticas públicas de educação ambiental enquanto constitutivas e constituídas pelas políticas de educação que são configuradas sob certa conformação do Estado. O artigo conclui que as políticas de educação ambiental, em termos discursivos, aglutinam, sem mediação crítica, princípios educacionais de diferentes matrizes de pensamento (histórico-crítica, sistêmica, pragmática etc.), e são promovidas sob os preceitos do Estado gerencial e da ideologia da Terceira Via.
\end{abstract}

Palavras-chave: Educação Ambiental, Política Pública, Secretaria de Educação de Santa Catarina.

\begin{abstract}
This paper analyzes the process of construction of the public policies of environmental education of the Santa Catarina's Department of Education, taking as starting point the year 1991, when the first curricular proposal was elaborated. The research used documentary analysis as a methodological framework. The paper's argument starts from the understanding of the public policies of environmental education as constitutive and constituted by the educational policies that are configured under certain conformation of the State. The article concludes that environmental education policies, in discursive terms, agglutinate, without critical mediation, educational principles from different matrices of thought (historical-critical, systemic, pragmatic, etc.) and are promoted under the precepts of the managerial state and Ideology of the Third Wave.
\end{abstract}

Keywords: Environmental Education, Public Policy, State of Santa Catarina.

\section{INTRODUÇÃO}

Este artigo analisa o processo de construção das políticas públicas de educação ambiental da Secretaria de Educação da rede estadual de Santa Catarina, em um esforço de pesquisa que utilizou a análise documental como estratégia metodológica. Por meio da apreensão e explicitação de determinações que interagem na produção de tais políticas, a partir da perspectiva do materialismo histórico dialético, em especial das

\footnotetext{
${ }^{1}$ Mestranda em Educação do Programa de Pós-Graduação em Educação - PPGE/UFRJ. Integrante do Laboratório de Educação, Ambiente e Sociedade - LIEAS. E-mail: adrianalimamoraes@hotmail.com

2 Professor do Programa de Pós-Graduação em Educação - PPGE/UFRJ. Pesquisador CNPq 1D. Líder do Laboratório de Investigações em Educação, Ambiente e Sociedade - LIEAS. E-mail: fredericoloureiro89@gmail.com
} 
contribuições de Antônio Gramsci, a investigação constituiu-se em um estudo de caso, cujo recorte toma como ponto de partida a elaboração da primeira proposta curricular da Secretaria estadual de Educação de Santa Catarina, publicada no ano de 1991.

A escolha desse documento como fundamento e fonte delimitadora de pesquisa foi em função de a proposta curricular, elaborada com a participação dos trabalhadores da educação, ter-se configurado em um documento legítimo com diretrizes e princípios norteadores para a condução dos processos educacionais na rede estadual de ensino. Cabe destacar que as principais categorias que compõem a proposta curricular foram sistematizadas de modo a absorver os pressupostos teóricos e metodológicos do materialismo histórico dialético, sendo evidente o uso de autores como Gramsci e Vygotsky e da pedagogia histórico-crítica.

A análise aqui operada foi direcionada por indagações de pesquisa: Como aconteceram e ainda se processam as políticas de educação ambiental na Secretaria de Educação? Apesar da adoção de uma proposta curricular com base epistemológica histórico-crítica, na materialidade, qual é a corrente hegemônica prevalecente nas ações de políticas públicas de educação ambiental?

No âmbito metodológico foram pesquisados documentos relacionados às políticas de educação ambiental, entre eles instrumentos orientadores, comunicações internas, ofícios, apresentações em slides, contemplando uma gama variada de fontes, que pudessem auxiliar na síntese de compreensão do entendimento da Secretaria a respeito da educação ambiental para as escolas da rede. Assim, todas as versões da Proposta Curricular de Santa Catarina foram analisadas, desde a primeira versão de 1991 até as posteriores versões que foram atualizadas, referentes aos anos de 1998, 2005 e 2014. Também foram analisadas comunicações internas e ofícios expedidos pela Secretaria, apresentações em slides e projetos institucionais encaminhados para as Gerências de Educação, incluindo entre esses o último elaborado pela SED, o projeto institucional Escola Educadora Sustentável e Promotora de Saúde. Também foram reunidos e analisados documentos legais associados à gestão da Secretaria, relativos a mudanças organizacionais ocorridas, a Lei Complementar $n^{\circ} 668$, de 28 de dezembro de 2015 e, de forma mais abrangente, sobre as modificações na administração pública do Estado, por intermédio da Lei Complementar $\mathrm{n}^{\mathrm{o}} 284$, de 28 de fevereiro de 2005. No âmbito orçamentário foram consultadas as fontes oficiais do Tribunal de Contas de 
Santa Catarina, nos dados em que consta a contabilidade do Estado, no que se refere à aplicação de recursos de forma específica da área de educação ambiental. Para isso utilizou-se o Sistema Integrado de Planejamento e Gestão Fiscal, o SIGEF. Ainda no campo orçamentário, os arquivos disponíveis na Gerência de Administração Financeira da SED foram disponibilizados para consulta.

A análise foi baseada na concepção gramsciana de Estado e de sociedade civil, como também nas suas categorias correlação de forças e sociabilidade. Essas categorias foram decisivas na percepção das controvérsias observadas entre o discurso institucional sobre as políticas e o seu desenvolvimento.

Os resultados indicam que a organização gerencial do Estado em Santa Catarina, sob o neoliberalismo, a partir de meados da década de 1990, ressignificou o sentido do que é público e privado, em um movimento de desresponsabilização do Estado, de parceria que implica a subordinação do público aos interesses particularistas do privado e da minimização das políticas públicas, reduzidas à lógica de projetos e prestação de serviços. A educação ambiental, enquanto uma das políticas públicas da educação reproduz largamente esse padrão, agravado pelo discurso do ambiente como algo que nos une acima dos conflitos sociais e pela baixa politização do próprio campo.

A relevância da pesquisa está no ineditismo do foco de estudo e na possibilidade de contribuição junto aos que trabalham na Secretaria, nas regionais de ensino e nas escolas da rede, a partir de uma compreensão crítica dos processos, avanços e dilemas acerca das políticas de educação ambiental em Santa Catarina, podendo, assim, produzir aprendizados significativos para os que estão diretamente ligados a essa atividade e para outros que possam interessar-se pelo tema.

\section{QUADRO TEÓRICO DE EMBASAMENTO DAS ANÁLISES DE PESQUISA}

A partir do campo epistemológico e metodológico do materialismo histórico dialético e da Educação Ambiental Crítica, cuja análise se debruça sobre o domínio das políticas públicas de educação ambiental, esta pesquisa considera a premência de uma análise que faça as relações entre os vários elementos que dialogam com o objeto de estudo, tendo no horizonte a apreensão da totalidade dos fenômenos estudados. Para isso considera imprescindível, em primeiro passo, conceituar política pública, Estado e sociedade civil, com base no quadro teórico escolhido. No que concerne à política 


\title{
AMBIENTE \& EDUCAÇÃO
}

ISSN- 1413-8638

E-ISSN - 2238-5533

v. 22, n. 2, p. 191-207, 2017

pública, a ênfase situa-se nas discussões e na análise a respeito da preservação do caráter público da política, apresentando a dialética do traço privatista e particularista das políticas públicas. Assim, as análises empreendem os estudos teóricos relacionados ao conceito ideológico, político e histórico da construção e operacionalização das políticas.

Com tais características, partindo desse quadro teórico, pensar a realidade implica considerar que ela é fruto de diversas mediações, determinadas pela conjuntura histórica que está inserida e, portanto, pressupõe compreendê-la dentro de uma totalidade histórica, na qual está em jogo uma rede de dinâmicas complexas: sociais, políticas, econômicas que engendram e compõem essa realidade. Dessa maneira, o conceito de Estado configura-se em dinâmica e entrelaçamento com a sociedade civil, estando para além do organismo estatal e da sociedade política, o que Gramsci chama de Estado integral ou ampliado.

Sendo assim, por Estado "deve-se entender, além do aparelho de governo, também o aparelho 'privado' de hegemonia ou sociedade civil." (Gramsci, 2000: p. 159). Isto é, concebê-lo em uma composição ampliada, determinado por seu caráter burguês no capitalismo, que se estrutura mediante o conflito entre diversos agentes que disputam por hegemonia. Nesta formulação, a ideia de consenso está implícita, uma vez que coloca nessa dimensão a percepção complexa dos direcionamentos de diferentes agentes numa direção de disseminar para as diversas classes e grupos sociais um modelo de sociabilidade que seja de interesse da classe dirigente. Nesse aspecto, partilhando da ideia de uma sociedade diversa e contraditória, Gramsci apresenta a categoria de correlação de forças, atravessada pelos contextos econômico e ideológico, na dinâmica da luta de classes.

\begin{abstract}
A concepção gramsciana de Estado ampliado (sociedade política + sociedade civil) é, portanto, um campo de intensas relações de força, espaço de disputa da hegemonia e de luta de classes. O momento unificador entre sociedade política e sociedade civil se expressa na realização da supremacia por um determinado grupo social, através do domínio ou da direção intelectual e moral. A relação de supremacia mais consensual e menos coercitiva é própria da correlação de forças entre as classes sociais na disputa pela hegemonia em diferentes conjunturas. (Oliveira e Bergue, 2012: p.17)
\end{abstract}

Nesse sentido, pode-se dizer que "Estado $=$ sociedade política + sociedade civil, isto é, hegemonia couraçada de coerção”. (Gramsci, 2000: p. 152). Sendo assim, nessa coalisão ou unidade dialética entre a sociedade política e a sociedade civil na 
conformação do Estado e o seu papel sedimentado na difusão de uma determinada ideologia, destaca-se o seu papel educador. Como explicita Gramsci, o "Estado tem e pede o consenso, mas também 'educa' este consenso através das associações políticas e sindicais, que, porém, são organismos privados, deixados à iniciativa privada da classe dirigente." (Gramsci, 2000: p. 65) Essa classe dirigente é a classe burguesa, que "põe-se a si mesma como um organismo em contínuo movimento, capaz de absorver toda a sociedade, assimilando-a a seu nível cultural e econômico; toda a função do Estado é transformada: o Estado torna-se 'educador'." (Gramsci, 2000: p. 171)

Nessa composição e educação política em que o Estado busca estratégias educativas e formativas, com vistas ao consenso, é significativo ter em perspectiva os processos não-aparentes, os que universalizam-se e conservam a hegemonia, os voltados a ações de conformação da sociedade, de novos tipos de humanidade. Essas ações, denominadas por Neves (2015) de Pedagogia da Hegemonia, colocam em evidência o pano de fundo que orienta a disseminação da pedagogia do consenso, com vistas a um novo tipo de sociabilidade a serviço do capital.

O termo Pedagogia da Hegemonia está vinculado à formulação de Gramsci de Estado ampliado e educador, decorrente da politização da sociedade civil e do reaparelhamento do Estado, com vistas ao domínio da direção cultural, intelectual, política e ideológica, de modo a elaborar um novo ideário que contemple um novo tipo de ser humano, adequado a um novo tipo de trabalho e processo produtivo, na lógica neoliberal. Nesse sentido, conforme afirma Gramsci, o "Estado é todo o complexo de atividades práticas e teóricas com as quais a classe dirigente não só justifica e mantém seu domínio, mas consegue obter o consenso ativo dos governados.” (Gramci, 2000: p. 212)

Nessa compreensão, é necessário colocar na discussão a categoria gramsciana de sociabilidade, que está relacionada à dinâmica social e ao processo de educação social que se opera no campo ideológico, por intermédio de regras reais e simbólicas. André Martins lembra que,

A sociabilidade é uma construção histórica produzida coletivamente, envolvendo relações de poder e refletida em cada sujeito singular por diferentes mediações, expressando, assim, um ordenamento mais ou menos comum sobre as formas de sentir/pensar/agir. (Martins, Em: http://www.sites.epsjv.fiocruz.br/dicionario/verbetes/socneo.html, Acesso em 11 de fevereiro de 2017) 
Assim, de forma recíproca, essas regras vinculam-se às constituições das individualidades e subjetividades, por meio de valores, representações e a construção de um imaginário, que influenciam de forma mais abrangente as experiências sociais, históricas e culturais dos seres humanos.

\section{O MODELO GERENCIAL DE ESTADO E OS PRECEITOS DA TERCEIRA VIA}

Como meio de estabelecer um único formato e diretriz, na busca de redefinir estratégias e legitimar o consenso por meio de um projeto político a serviço da sociabilidade burguesa, no início da década de 90 uma nova agenda é inserida no campo político e econômico brasileiro, como um importante instrumento de disseminar um novo modelo societário, no viés de uma nova pedagogia da hegemonia. Esse modelo, denominado de Terceira Via, está relacionado a forças sociais ligadas ao ideário da governança progressista que, apesar de estar em sintonia com as questões centrais do neoliberalismo, busca ajustar processos, conciliar conflitos, no intuito de reformar a governabilidade do capitalismo, mediante políticas que reduzam a grande contradição existente nele, de maneira a torná-lo mais adequado à humanidade.

A política da Terceira Via orienta um programa que possibilite um reordenamento político, econômico e das relações entre os sujeitos sociais, num movimento que pretende instaurar um novo projeto societário que tenha um alcance globalizado. Esse projeto sustenta a necessidade de uma reforma estatal, que considere a construção de um novo Estado democrático, capaz de sintonizar-se com organismos da sociedade civil, por intermédio da ampliação de espaços de participação, numa articulação direta entre a esfera estatal e a privada.

A articulação com a sociedade civil está associada a um pressuposto que considera a premência na construção de uma cidadania ativa, uma sociedade civil ativa, que é assimilada na perspectiva de uma renovação de uma cultura cívica, em que incorpore nos sujeitos sociais o ideário do trabalho em parceria, em um pacto social que incentive o apaziguamento de conflitos. É o incentivo a uma nova postura humana, numa lógica nova de sociabilidade, que oriente para uma coesão social e o resgate de formas de solidariedade entre as classes sociais, com vistas à promoção de um bem comum. Nesse horizonte, a criação de novos organismos sociais é estimulada e estes aparecem no formato de novos sujeitos coletivos, que atuam num regime de 
colaboração social, a partir do incentivo e do fortalecimento de uma economia mista e de um processo de confiança ativa, que tenha em vista a busca de um equilíbrio entre os sujeitos sociais e a esfera estatal.

$\mathrm{Na}$ perspectiva da visão de mundo que sustenta a Terceira Via, o campo hegemônico concebe a abertura de novos contextos discursivos, disseminados por meio de novas estratégias, que busquem uma conformação social pautada na concórdia entre as classes e no consenso ideológico. Nesse cenário, a educação ambiental foi uma das temáticas cooptadas como estratégia de disseminação do novo projeto de sociabilidade do capital.

\section{A CONSTRUÇÃO DAS POLÍTICAS DE EDUCAÇÃO AMBIENTAL DA SECRETARIA ESTADUAL DE EDUCAÇÃO: UMA ANÁLISE CRÍTICA}

Iniciada a partir das reformas na educação ocorridas em meados da década de 80, após o período ditatorial no Brasil, diferentes movimentos empreenderam-se no País com a finalidade de promover uma revisão curricular que pudesse ter em pauta a universalização de direitos ligados aos interesses dos trabalhadores, por meio da oferta de um ensino público crítico, dentro e a partir da atuação da escola pública. Nesse tempo diversos grupos ligados a um pensamento de centro-esquerda ingressaram na coordenação de diversas secretarias estaduais no Brasil, à frente da formulação de novas propostas curriculares, que tivessem em seu ideário os interesses da classe trabalhadora. Em Santa Catarina lideranças ligadas a esse pensamento trabalharam no sentido de considerar a educação pública formal como um espaço de propiciar o acesso ao conhecimento socialmente produzido, além de outros que pudessem permitir a reflexão sobre a sociedade de seu tempo e as suas contradições intrínsecas, o que sedimentou e deu vazão a todo o processo de discussão e construção de uma proposta educacional histórico-crítica, inspirada pelo pensamento de Gramsci e de Vygotsky.

Essa compreensão considera o sentido político do fazer educacional, compreendendo que a oferta igualitária na produção e apropriação de conteúdos culturais e científicos relevantes entre as classes dominantes e as classes subalternas possibilita formas de luta política voltadas para a superação das relações de expropriação e dominação no capitalismo. Nessa propositura, a Proposta Curricular de Santa Catarina (PCSC) foi pensada a partir da concepção de uma escola pública que tivesse uma ação mais integrada, com caráter transformador e emancipatório. Em outras 
palavras, pensada sob aspectos filosóficos, históricos e específicos das áreas do conhecimento, tendo como horizonte a compreensão de que a constituição da subjetividade humana dá-se numa relação dialética entre a atividade do sujeito e o seu contexto cultural, bem como na construção dos sentidos subjetivos de sua práxis, a partir dos contornos do mundo objetivo.

Dentro desses pressupostos, destaca-se na PCSC a totalidade como categoria do materialismo histórico e o próprio método dialético como forma de apreensão da realidade, que é pensada a partir da percepção "de que homem, mundo e sociedade estamos falando?", tendo em conta que a totalidade social é um retrato de múltiplas e complexas relações e determinações, elemento essencial para a apreensão da natureza constitutiva do conhecimento. No processo de ensino e aprendizagem, isso se traduz no resgate ao conhecimento científico, a pesquisa como elemento metodológico e a interdisciplinaridade como uma estratégia para superar a fragmentação do conhecimento e as atividades individuais, em favor de uma visão coletiva da totalidade. Nessa perspectiva, a apropriação do conhecimento nos conteúdos disciplinares deve integrarse entre si e em diálogo entre os saberes e junto às vivências e à realidade concreta dos estudantes, em uma visão crítica e dinâmica do mundo físico e social, situado num determinado tempo histórico.

Para isso, compreende-se necessário que a escola trabalhe numa concepção problematizadora, que permita a crítica e a reflexão acerca do ambiente e da sociedade, numa ótica ampla da realidade, de modo a produzir conhecimentos não-prontos, mas abertos. Nesse aspecto, o processo de ensino e aprendizagem favorece uma práxis participativa, tendo na realidade concreta o ponto de partida para a investigação dos aspectos significativos das situações de estudo, aproximada da realidade intelectual, cultural e social do estudante. No que concerne à prática pedagógica escolar, considerase o projeto político pedagógico como o elemento aglutinador, um instrumento de planejamento e de avaliação dos processos pedagógicos da escola, cujos referenciais educativos pautam-se em planos de ensino fundamentados em um currículo integrado e a escola, por meio dos seus sujeitos curriculares, autora da construção de seu caminho educativo.

A edificação dessa nova lógica educacional ocorreu sob a coordenação da Secretaria de Educação, por meio do direcionamento de um grupo de intelectuais 
orgânicos afinados à tradição marxista e à pedagogia histórico-crítica. Em processos de movimentação em formação continuada para os educadores da rede, as ações conduzidas, relativas à proposta curricular em nível de produção coletiva, buscou para além de uma ação meramente pedagógica estimular o entendimento acerca do papel social da escola, do educador e do segmento da sociedade que a escola pública atende. Dito de outro modo, buscou colocar em evidência a função pública do fazer educativo, do qual considerava-se que nenhum trabalhador da educação poderia alienar-se. Tratava-se de assumir uma postura político-pedagógica para dar conta do ato pedagógico, um projeto que tinha em vista a hegemonia dos interesses das classes populares.

Desde então, nos seus vinte e quatro anos de percurso, a PCSC foi sendo atualizada em intervalos e períodos ligados a gestões com maior abertura para um trabalho a partir dessa perspectiva, em grande parte, nos governos do PMDB, que continham dentro do partido a presença do referido grupo de intelectuais orgânicos. (Hentz, 2012) No entanto, sob a influência do modelo gerencial de Estado adotado no Brasil e em Santa Catarina no início da década de 90, a concepção curricular e o fazer educativo da Secretaria sofreram outras influências e pressões, incorporando um modelo de gestão que acabou por realizar um movimento de aglutinação de diversas demandas recebidas da sociedade civil e do próprio aparato do Estado, na construção de suas políticas de educação. Isso é perceptível nos documentos que tratam sobre as políticas de educação ambiental, bem como nos conteúdos das versões da PCSC posteriores, em que aparecem agrupamentos de questões epistemológicas de diferentes matrizes ideológicas.

No que diz respeito à PCSC, as influências do materialismo histórico dialético e dos preceitos neoliberais da Terceira Via coexistem nos documentos sem que haja uma mediação crítica e acontecem mais especificamente a partir da segunda versão. A primeira versão tem em sua construção traços mais voltados às concepções marxistas de educação e, embora não apresente destacadamente a educação ambiental como um campo, contempla, nas disciplinas curriculares, as discussões a respeito da problemática socioambiental. Nas demais versões, em que a educação ambiental é destacada como um campo epistemológico e metodológico, fica visível a miscelânea teórica que 
condensa concepções controversas, como é o caso da abordagem sistêmica, que diverge em raiz da abordagem marxista, no que diz respeito à compreensão da sociedade.

A versão de 2014, última atualização realizada, demonstra aspectos de influência do Ministério da Educação, cujo modelo de coparticipação condiciona a adesão às políticas federais, por meio de repasses de recursos aos estados, delineando, com isso, um cenário em que as políticas são construídas de forma vertical (de cima para baixo), numa lógica gerencial apaziguadora dos conflitos e das lutas por direitos. Essas políticas federais "abafam" controvérsias com as construções locais e enfraquecem a autoria daqueles que estão nos processos de base, partícipes da construção de políticas a partir da materialidade vivida no chão da escola. Essa questão é constatada nos documentos pesquisados acerca de investimentos relativos à educação ambiental, utilizando-se como fonte de pesquisa os arquivos do Tribunal de Contas e da Supervisão de Administração e Finanças da Secretaria. Nesse banco de dados não foram encontrados quaisquer recursos investidos em educação ambiental sob o vínculo da Secretaria de Educação, tendo sido apenas encontrados recursos que demonstram que nos últimos cinco anos todos os investimentos ocorridos foram financiados por recursos federais, a partir do Plano de Ações Articuladas ${ }^{3}$. Os investimentos ocorreram nos anos de 2013, 2014 e 2016, conforme demonstra o quadro 1.

Quadro 1 - Recursos alocados para ações de educação ambiental na SED

\begin{tabular}{|c|c|c|}
\hline Ano & Ação & Valor de pagamento \\
\hline 2013 & $\begin{array}{c}\text { Organizar e realizar as Conferências regionais e estaduais } \\
\text { infanto-juvenis pelo Meio Ambiente. }\end{array}$ & $\mathrm{R} \$ 207.248,00$ \\
\hline 2013 & $\begin{array}{c}\text { Implantar políticas para a formação de professores, visando } \\
\text { ao cumprimento das Leis 9.765/99, 10.639/03 e 11.545/08. }\end{array}$ & $\mathrm{R} \$ 1.332 .880,80$ \\
\hline 2014 & $\begin{array}{c}\text { Curso de formação continuada: Diversidade, Educação } \\
\text { ambiental e marcos legais no currículo da educação básica. }\end{array}$ & $\mathrm{R} \$ 784.531,27$ \\
\hline 2016 & Caderno pedagógico de Educação e Diversidade. & $\mathrm{R} \$ 8.520,00$ \\
\hline
\end{tabular}

Fonte: Arquivos disponibilizados pela Supervisão de Administração e Finanças da SED

A obtenção de recursos para o desenvolvimento de ações de educação ambiental, advindos exclusivamente do Ministério da Educação, aponta o painel de vulnerabilidade

\footnotetext{
3 “O PAR é definido como "o conjunto articulado de ações, apoiado técnica ou financeiramente pelo Ministério da Educação, que visa ao cumprimento das metas do Compromisso e a observância das suas diretrizes" (Brasil, 2007). Trata-se de um processo de planejamento concebido pelo MEC por meio de um instrumento dividido em quatro dimensões: gestão educacional, formação de professores e profissionais de serviços e apoio escolar, práticas pedagógicas e avaliação e infraestrutura física e recursos pedagógicos.” (Souza, 2011: p. 07)
} 
desse processo, que se alia às constantes mudanças organizacionais ocorridas na gestão da Secretaria. Atendendo atualmente 1080 (um mil e oitenta) escolas da rede pública estadual, a Secretaria de Educação conta com uma estrutura que abrange o Secretário Estadual de Educação e a sua equipe de gabinete, sete diretorias e suas respectivas gerências e o Instituto Estadual de Educação. Essas diretorias contemplam as pastas de administração e finanças, de gestão de pessoas, de gestão de rede estadual, de articulação com os municípios, de tecnologia e inovação, de políticas e planejamento educacional e de infraestrutura escolar. A atual estrutura organizacional estabeleceu-se mediante a instituição do novo Quadro de Pessoal do Magistério Público Estadual, conforme a Lei Complementar $n^{\circ}$ 668, de 28 de dezembro de 2015.

Nessa nova composição, a educação ambiental integra-se em duas supervisões: Gestão de Rede e de Políticas e Planejamento Educacional. Isto porque a primeira envolve-se na operacionalização dos programas e projetos junto às escolas, e a segunda situa-se na organização e no planejamento de políticas públicas de capacitação e formação continuada na área. Refletindo sobre esse aspecto, o "planejar" e o "realizar", estando sob a responsabilidade de dois setores distintos, podem propiciar um terreno ainda mais fragmentado no contexto educacional, caso não haja um diálogo constante entre os dois setores e uma leitura de realidade no planejamento das políticas.

Esse modelo fragmentário de gestão é percebido no processamento histórico de institucionalização da educação ambiental na Secretaria que, desde a década de 1980, sofre modificações na forma de gestão, ocorridas por meio de influências externas e internas num processo de correlação de forças, podendo ser observada no quadro a seguir.

Quadro 2 - Processo de institucionalização da educação ambiental na SED

\begin{tabular}{|c|c|c|}
\hline $\begin{array}{c}\text { Institucionalização da Educação } \\
\text { Ambiental na SED }\end{array}$ & Período & Possíveis influências \\
\hline $\begin{array}{c}\text { Criação do Núcleo de Educação } \\
\text { Ambiental (NEA). }\end{array}$ & $\begin{array}{c}\text { Década } \\
\text { de } 80\end{array}$ & $\begin{array}{c}1981 \text { na instituição da Política Nacional do } \\
\text { Meio Ambiente (PNMA). }\end{array}$ \\
\hline $\begin{array}{c}\text { Alteração do NEA para Grupo de } \\
\text { Trabalho de Educação Ambiental } \\
\text { (GTEA). }\end{array}$ & 1991 & $\begin{array}{c}\text { Publicação da Primeira Proposta Curricular de } \\
\text { Santa Catarina. }\end{array}$ \\
\hline $\begin{array}{c}\text { Alteração do GTEA para Grupo } \\
\text { Multidisciplinar de Educação Ambiental. }\end{array}$ & 1998 & $\begin{array}{c}\text { Período de publicação da primeira atualização } \\
\text { da Proposta Curricular de Santa Catarina. }\end{array}$ \\
\hline $\begin{array}{c}\text { O Grupo Multidisciplinar de educação } \\
\text { ambiental reorganiza-se novamente } \\
\text { como NEA. }\end{array}$ & 2003 & $\begin{array}{c}\text { Período de elaboração da terceira versão da } \\
\text { proposta, publicada em 2005. } \\
\text { Construção da Agenda 21 Catarinense }\end{array}$ \\
\hline
\end{tabular}




\begin{tabular}{|c|c|c|}
\hline & & $\begin{array}{c}\text { Lançamento da I Conferência Infanto-Juvenil } \\
\text { pelo meio ambiente. } \\
\text { Lançamento do Projeto AMBIAL }{ }^{4} \text {. }\end{array}$ \\
\hline $\begin{array}{c}\text { O NEA deixa de existir e passa a integrar } \\
\text { a Coordenadoria de Projetos } \\
\text { Multidisciplinares. } \\
\end{array}$ & 2007 & $\begin{array}{l}\text { A pesquisa não teve alcance nas motivações } \\
\text { de mudanças organizacionais. }\end{array}$ \\
\hline $\begin{array}{c}\text { Extingue-se as coordenadorias, que } \\
\text { passam a ser chamadas de Articulação } \\
\text { das Diversidades, englobando a educação } \\
\text { ambiental e outras temáticas relacionadas } \\
\text { à pasta. }\end{array}$ & 2011 & $\begin{array}{l}\text { A pesquisa não teve alcance nas motivações } \\
\text { de mudanças organizacionais. }\end{array}$ \\
\hline $\begin{array}{l}\text { O NEA SED foi reativado, também } \\
\text { como diretriz para as Gerências de } \\
\text { Educação e escolas. }\end{array}$ & 2012 & $\begin{array}{c}\text { Contexto de lançamento da versão preliminar } \\
\text { do Programa Escolas Sustentáveis e das } \\
\text { orientações da IV Conferência Infanto-Juvenil } \\
\text { pelo Meio Ambiente. }\end{array}$ \\
\hline $\begin{array}{l}\text { A educação ambiental já não atua por } \\
\text { meio de NEA e esta divide-se sob a } \\
\text { responsabilidade de duas gerências: a de } \\
\text { Ensino Médio e de Jovens e Adultos. }\end{array}$ & 2013 & $\begin{array}{l}\text { A pesquisa não teve alcance nas motivações } \\
\text { de mudanças organizacionais. }\end{array}$ \\
\hline $\begin{array}{l}\text { Com a instituição de uma nova estrutura } \\
\text { organizacional na SED, a educação } \\
\text { ambiental situa-se na Diretoria de } \\
\text { Política e Planejamento Educacional e } \\
\text { Diretoria de Gestão de Rede. }\end{array}$ & 2014 & $\begin{array}{l}\text { A pesquisa não teve alcance nas motivações } \\
\text { de mudanças organizacionais. }\end{array}$ \\
\hline Reativa-se novamente o NEA SED. & 2016 & $\begin{array}{c}\text { No mesmo contexto da atualização da } \\
\text { Proposta Curricular em 2014, quando um dos } \\
\text { temas centrais desse documento estava } \\
\text { dedicado a discutir as questões de diversidade, } \\
\text { nesse tempo cogitou-se a reativação do NEA, } \\
\text { numa compreensão de que essa temática } \\
\text { deveria perpassar todos os setores da } \\
\text { Secretaria. }\end{array}$ \\
\hline
\end{tabular}

Fonte: SED, 2016.

Nessas idas e vindas e mudanças do componente de gestão da educação ambiental na Secretaria, é interessante observar a influência da proposta curricular na composição e reativação de grupos gestores (sob diversas nomenclaturas), levando em conta que as modificações de composição ocorreram em períodos semelhantes aos da criação e atualização da PCSC. Do mesmo modo, aparecem influências de movimentos ligados à ideologia da Terceira Via, como é o caso da Agenda 21 Estadual das Conferências Infanto-Juvenil pelo Meio Ambiente, ação do Ministério da Educação.

\footnotetext{
${ }^{4}$ O projeto AMBIAL, elaborado pela Secretaria de Educação em parceria com o governo federal, buscou aliar a segurança alimentar e hábitos nutricionais adequados a ações relativas ao combate à fome e ao desperdício de alimentos, por meio do aproveitamento integral dos alimentos. O projeto foi instalado em escolas-piloto, inseridas em regiões de baixo IDH (Índice de Desenvolvimento Humano), em todo o Estado de Santa Catarina.
} 
No âmbito de mudanças ocorridas na administração pública do Estado, mediante a Lei Complementar $n^{\circ} 284$, de 28 de fevereiro de 2005, é possível observar, igualmente, os contextos de influência de fragmentação do modelo de gestão neoliberal. Na criação de uma nova configuração de gestão para a Administração Pública Estadual de Santa Catarina, em 2005 foram criadas as Secretarias de Estado de Desenvolvimento Regional (SDR), atualmente denominadas de $\mathrm{ADR}^{5}$ (Agência de Desenvolvimento Regional). Em uma proposta de desenvolvimento regional, cujo objetivo estava em "desburocratizar, descentralizar e desconcentrar os circuitos de decisão melhorando os processos, a colaboração entre os serviços, o compartilhamento de conhecimento e a correta gestão da informação" (Lei Complementar n 284, de 28 de fevereiro de 2005), a descentralização e desconcentração administrativa passam a ser coordenadas pelas Secretarias de Estado de Desenvolvimento Regional, subdividindo a responsabilidade de coordenação com as Secretarias setoriais, cujo papel é formular, normatizar e controlar as políticas públicas. Já em nível regional, por meio das SDRs/ADRs, a responsabilidade configura-se em implementar essas políticas regionalmente.

No regimento interno que orienta as ações das ADRs, a educação ambiental é mencionada no Art. 52, que trata das responsabilidades dos Integradores Educacionais, cargos comissionados subordinados ao supervisor de Gestão de Rede na Gerência de Educação. No regimento não está colocado claramente qual ou quais os setores são responsáveis pela temática, apenas que são de responsabilidade desse cargo o acompanhamento e a avaliação acerca da implementação das políticas de educação ambiental. Ainda no Art. 3 do referido regimento, é de responsabilidade da ADR "viabilizar instrumentos de desenvolvimento econômico sustentável para a geração de novas oportunidades de trabalho e renda, promovendo a equidade entre pessoas e entre seus Municípios" (Santa Catarina, 2016: p. 02) e no Art. 46, a orientação para a Gerência de Educação articula-se com a Secretaria de Desenvolvimento Sustentável. Entretanto, apesar de haver essas menções que posicionem a temática ambiental de forma mais abrangente, em síntese a educação ambiental na gestão da educação está

\footnotetext{
${ }^{5}$ Nos seus quatorze anos de existência ocorreram movimentos questionando a eficácia e a necessidade da manutenção das SDRs, tendo em vista o alcance incipiente no desenvolvimento regional e à democratização da gestão, contando com uma estrutura de alto custo para o Estado. Em 2015, foi apresentado pelo Governo na Assembleia Legislativa, um projeto que propôs alterar a estrutura da SDR, mudando seu status de secretaria para agência (Agência de Desenvolvimento Regional), buscando reduzir, com isso, custos e agilizar o trabalho desses órgãos. Aprovado o projeto proposto pelo governo, no Decreto n ${ }^{\circ} 856$, de 6 de setembro de 2016 e publicado no Diário Oficial do dia 8 de setembro de 2016.
} 
alocada como um tema de alcance pedagógico, inserida na atribuição de um cargo subordinado à Gerência de Educação. Sendo assim, a educação ambiental ou o contexto da sustentabilidade não estão inseridos como uma política transversal, que perpassa todos os setores da administração pública, nem tampouco orienta os processos de gestão das ADRs, como também nas suas respectivas Gerências de Educação.

Essa fragmentação e dispersão das ações no campo, influenciadas por esse modelo de administração que pulveriza as responsabilidades e as ações em diversas instâncias, agências, setores e diretrizes, potencializa-se mediante a fragilidade no âmbito orçamentário. Sob o ideário da Terceira Via, a educação ambiental é posta como uma área de ação em conjunção entre o Estado e a sociedade civil e, portanto, a lógica de investimento organiza-se nos moldes de parceria público/privada. Em contrapartida, mediante o modelo orçamentário brasileiro, cuja tradição governamental volta-se para ações de gestão momentâneas e de alcance de curto prazo, a educação ambiental, por configurar-se como uma atividade de longo e médio prazos, exerce pouca influência e pressão no campo político e econômico e, por isso, não é considerada como um processo prioritário nas escolhas para os investimentos públicos governamentais.

Portanto, é nesse campo de contradições que se encontram a Secretaria de Educação e a educação ambiental, que sofrem os reflexos da fragmentação que ocorre no Estado neoliberal, que se subdivide em compartimentações que desagregam a conjuntura pública das políticas, dificultando a percepção das temáticas em sua totalidade. As políticas públicas de educação ambiental refletem o processo de correlação de forças, em uma síntese originada no atendimento a diversas demandas e atores vindos da comunidade educacional, da sociedade civil e da sociedade política e apresentam-se divergentes em essência da PCSC, uma vez que partem de processos verticais e idealizados em sua elaboração. Este movimento contraditório acaba por promover uma autonomia relativa à escola e ao educador, num olhar que preconiza a execução de modelos ideais de escola, elaborados fora do espaço escolar, numa ótica de serem implementados pelas escolas.

Essa lógica, que tem em seu direcionamento a composição hierárquica, considera a centralização dos órgãos educacionais e as suas esferas de poder, numa racionalidade de repasse e execução de ações pré-concebidas, a serem articuladas sob um comando centralizador. Isto se apresenta por meio de políticas que se afinam com os 
preceitos ideológicos da Terceira Via, assentados na lógica de cogestão entre o Estado e a sociedade civil, entendidos como instâncias separadas da sociedade, que podem relacionar-se harmonicamente e com base na conciliação de classes. Em outras palavras, desconsidera os conflitos estruturais de uma sociedade desigual, cujo Estado atende a interesses particularistas e privados na promoção das políticas públicas de educação, os quais, em função disso, atendem crescentemente aos interesses do mercado pela escola (transformação de um direito em serviço) e por determinada formação de mão de obra.

\section{CONSIDERAÇÕES FINAIS}

A Proposta Curricular de Santa Catarina, nascida de uma confluência favorável a um pensamento crítico no final da década de 1980 e no início da de 1990, no momento em que ocorria no campo político o processo de redemocratização no país e no campo acadêmico entravam os escritos de Gramsci, inseria-se também no cenário brasileiro o movimento de disseminação de uma nova conformação social, nos moldes do neoliberalismo da Terceira Via. É nesse universo contraditório que está inserida a Secretaria estadual de Educação de Santa Catarina e, portanto, é neste cenário que se analisa o desenvolvimento das políticas educacionais, em destaque neste artigo as políticas de educação ambiental.

Por meio de um processo de pesquisa, que buscou compreender as principais determinações que influíram na construção dessas políticas, bem como as controvérsias implícitas nesse processamento, a categoria gramsciana de correlação de forças e sociabilidade deram o direcionamento para as análises que concluíram que as políticas de educação ambiental da Secretaria de Educação da rede estadual de Santa Catarina são retratos de uma síntese de correlação de forças, que disputam por hegemonia. Essa síntese expressa elementos de uma proposta de educação histórico-crítica, criada para atender aos interesses das classes populares, o que demandaria, nesse aspecto, um fortalecimento do caráter público da educação catarinense. Em contrapartida, apresentam também elementos do modelo gerencial de Estado, num contexto de enxugamento no aparato público e no incentivo a parcerias entre o Estado e os diversos setores da sociedade civil, ou seja, entre a esfera pública e a privada. É nesse campo de contradições que se encontram a Secretaria de Educação e a educação ambiental, que sofrem os reflexos da fragmentação que ocorre no Estado neoliberal, que se subdivide em compartimentações que pulverizam a conjuntura pública das políticas. 
Desvinculada de recursos próprios, a educação ambiental apresenta-se fragilizada e diluída em um modelo de administração pública, subdividido em diversas agências, secretarias, setores, comissões, grupos, núcleos, dificultando, dessa forma, uma atuação a partir da perspectiva da totalidade. Sob a influência e a pressão de diversas fontes nessa correlação de forças, sob diferentes matrizes ideológicas, as orientações metodológicas nos documentos contradizem-se e demonstram esse processo de síntese, buscando abarcar vários elementos, de diferentes origens metodológicas. Se por um lado a orientação evidencia a construção de um projeto político pedagógico que tenha em sua base a autoria dos sujeitos curriculares que vivenciam a realidade escolar, por outro apresentam a solicitação de execução por parte das escolas, de programas construídos ideal e verticalmente por instâncias fora do ambiente escolar.

O modelo de planejamento e orçamento delineado pelo governo federal, que tem buscado a aprovação de medidas por meio de incentivos à subordinação dos estados a seus objetivos de reforma, guarda estreita relação ao federalismo fiscal, uma vez que estabelece uma conjuntura de dependência dos estados aos recursos vindos do governo central. Esse modelo contribui para a conformação de políticas sob um determinado contexto ideológico que, muitas vezes, chocam-se com concepções e políticas constituídas regionalmente, a partir de processos coletivos de base.

Assim, como já sinalizado, as políticas de educação ambiental da Secretaria de Educação manifestam-se a partir de uma síntese de correlações de forças, que ocorrem entre as influências de um modelo de gestão neoliberal, expressas nas questões estruturais da educação, como também nos elementos de uma educação histórico-crítica, gestada na caminhada de vinte e quatro anos de sua proposta de educação, expressa nos documentos da Proposta Curricular de Santa Catarina.

\section{REFERÊNCIAS}

GRAMSCI, A. Cadernos do cárcere: Maquiavel. Notas sobre o Estado e a política. Vol. 3. Rio de Janeiro, Civilização Brasileira, 2000.

HENTZ, P. Projetos Educacionais Populares no Contexto do Estado: Um Estudo da Proposta Curricular de Santa Catarina, Caçador, 2012.

KAPLAN, L. Análise crítica dos discursos sobre Estado e sociedade civil nas políticas públicas em Educação Ambiental. Florianópolis, V Encontro Nacional da Anppas, 2010. 
MARTINS, A. S. Sociedade Neoliberal. Disponível em: http://www.sites.epsjv.fiocruz.br/dicionario/verbetes/socneo.html, Acesso em $11 \mathrm{de} \mathrm{fev.}$ 2017.

NEVES, L. M. W. (Org.). A nova pedagogia da hegemonia: estratégias do capital para educar o consenso. São Paulo, Xamã, 2005.

OLIVERIA, M., BERGUE, S. T. Políticas públicas: definições, interlocuções e experiências. Caxias do Sul, Educs, 2012.

SANTA CATARINA. Em: http://www.sed.sc.gov.br/index.php/secretaria/historico. Acesso em 12 de fev. de 2017.

. Lei Complementar $n^{\circ}$ 284, de 28 de fevereiro de 2005. Estabelece modelo de gestão para a Administração Pública Estadual e dispõe sobre a estrutura organizacional do Poder Executivo. Florianópolis, Diário Oficial de Santa Catarina, 2005.

Lei Complementar $n^{\circ}$ 668, de 28 de dezembro de 2015. Dispõe sobre o Quadro de Pessoal do Magistério Público Estadual, instituído pela Lei Complementar $\mathbf{n}^{\mathbf{0}}$ 1.139, de 1992, e estabelece outras providências. Florianópolis, Diário Oficial de Santa Catarina, 2015.

Proposta Curricular de Santa Catarina: Uma contribuição para a escola pública do pré-escolar, $1^{\circ}$ grau, $2^{\circ}$ grau e educação de adultos. Florianópolis, COGEN, 1991.

Proposta Curricular de Santa: Educação Infantil, Ensino Fundamental e Médio: Temas Multidisciplinares. Florianópolis: COGEN, 1998.

Proposta Curricular de Santa Catarina: Estudos Temáticos. Florianópolis: IOESC, 2005.

Proposta Curricular de Santa Catarina: Formação Integral na Educação Básica. Florianópolis, 2014.

Decreto 856/2016. Florianópolis, Diário Oficial de Santa Catarina, 2016.

SED. Caderno Orientativo de Educação Ambiental, 2016.

SIGEF, Em: http://www.sigef.sef.sc.gov.br. Acesso em 28 de jul. de 2016.

SOUZA, B. J. R. O plano de ações articuladas (PAR) como instrumento de planejamento da educação: o que há de novo? Brasília, Universidade Católica de Brasília (UCB), 2011. 